\title{
Sustainability and the traditional tourism model in Baja California Sur, Mexico
}

\author{
P. Ganster ${ }^{1}$ \& A. Gámez ${ }^{2}$ \\ ${ }^{1}$ Institute for Regional Studies of the Californias, \\ San Diego State University, USA \\ ${ }^{2}$ Department of Economics, \\ Autonomous University of Baja California Sur, Mexico
}

\begin{abstract}
The traditional Mexican model for coastal tourism development that includes high rise beachfront hotels and urban infrastructure for visitors was extended to Baja California Sur in the 1970s by the national tourism ministry. Public infrastructure investment attracted financing from large private companies and tourism boomed, especially in the coastal corridor between Los Cabos and San José, where population grew at $10 \%$ per year and total visitors to the region reached 1.7 million by 2008 . Unintended negative effects of this development included environmental and social effects. Development in the coastal zone encroached onto the federal protected zone of $20 \mathrm{~m}$ above the high tide line (location of marine turtle nesting sites), restricted access for local people to beaches, deteriorated viewsheds, produced discharges of desalination brine into the nearshore marine environment, and destroyed areas of dune flora and fauna as well as cultural and archaeological sites. Social impacts included significant migration from other regions of Mexico, growth of unplanned residential areas without adequate urban services for tourism workers, and creation of employment opportunities that do not favor local people. The analysis demonstrates that Baja California Sur traditional tourism development presents a clear danger to the coastal zone environment of the region, with significant negative externalities that inevitably will reduce the attractiveness of the area for international tourism. Strategies for stakeholders in BCS to mitigate further environmental deterioration and negative social effects are presented.

Keywords: Baja California Sur, coastal tourism, environmental deterioration, social effects, megatourism projects, FONATUR, sustainability, regional development, Los Cabos.
\end{abstract}




\section{Introduction}

This paper examines the model of coastal tourism development widely employed nationally and in the Mexican state of Baja California Sur (BCS). It discusses the sustainability of this model with respect to the fragile coastal zone and regional environment as well as the social effects of such massive and rapid development.

Baja California Sur is the Mexican state that occupies the southern half of the peninsula of Baja California. It covers $3.8 \%$ of Mexican territory, but its small economy is just $0.6 \%$ of Mexico's GDP, number of businesses, and employment (data for 2006 [1, 2]). To the east is the Gulf of California, one of the most productive ocean environments in the world, to the west is the Pacific Ocean, and to the north is the Mexican state of Baja California. Baja California Sur's climate is arid. The rugged topography and landscape of the state is dominated by desert ecosystems with distinctive flora and fauna except for a few mountain tops that have greater rainfall. The first European inhabitants of the peninsula were those who came with Jesuit missionaries at the end of the $17^{\text {th }}$ century. For more than half a century, missionaries controlled the peninsula and a local culture based on ranching emerged. Subsistence ranching continued to be the main economic activity through independence in the early $19^{\text {th }}$ century and this persisted well into the $20^{\text {th }}$ century. Mining, the pearl oyster industry, and commercial fishing provided economic booms but tourism did not begin until the sportfishing emerged in the 1950s, first catering to USA clients who flew in from California and elsewhere to the north. A paved road did not connect Baja California Sur with Baja California and the United States until 1973 and sea connections across to the Mexican mainland were slow. Baja California Sur remained isolated and not until the 1980s was the region integrated into the international economy through the designation of the area as a free trade zone within Mexico and the growth of modern air transportation and expansion of tourism.

Governmental institutions in Baja California Sur were not well developed at the time that tourism in the region was beginning to expand. Baja California Sur only became a state in 1974, in a governance system tightly controlled from the national capital in Mexico City, although decentralization in government has been advancing slowly since the late 1980s. At statehood, BCS was politically divided into three municipalities or counties: Mulegé, Comondú, and La Paz, which was also the state capital. In 1981, Los Cabos became the fourth municipality, and Loreto joined as the fifth in 1992. Thus, at the time that tourism was taking off in Baja California Sur, local government was being rearranged, the state government was weak, and federal agencies in the state played an exceedingly large role. Key development decisions were made in Mexico City, rather than in the state capital or in the municipalities $[3,4]$.

\section{The Mexican model of tourism development}

Mexico's national tourism investment policy emerged in the 1960s and the 1970s as a complement to the national development policy of import substitution 
industrialization to address deficits in the balance of payments and uncontrolled growth of urban areas [5]. Luxury tourism catering to foreign visitors was seen as a way to stimulate regional economic development and create jobs [6]. It was also seen as a way to attract foreign and domestic investment for large, planned developments located in lightly populated coastal areas. FONATUR was created in 1974 to direct this effort and since that time has shown great continuity in terms of policies and projects [7]. FONATUR plans, develops, constructs, and operates hotels, provides subsidized loans to domestic and foreign investors, and provides infrastructure and ongoing maintenance [6]. From its inception, FONATUR has operated in a top-down, non-transparent, and statist fashion, determining the specifics of projects and imposing them with little input from local residents. In fact, FONATUR has demonstrated a willingness to pursue its tourism plans "despite opposition from societal groups, most commonly residents in targeted zones," [5].

In the late 1980s, globally and in Mexico, the concepts of sustainable development received much attention and FONATUR adopted the principles of sustainable tourism development. However, it appears that "sustainable development" practices were generally not implemented in FONATUR's many projects, although in the mid-1990s FONATUR initiated four new projects to decentralize tourism, set lower limits in carrying capacity, and promote nature tourism [7]. In 2012, the FONATUR website continued to emphasize the sustainability of its projects (www.fonatur.gob.mx).

By 2007, FONATUR had launched five resorts: Cancún, Ixtapa, Los Cabos, Loreto, and Huatulco [8]. Of these, Loreto lagged behind for various reasons but the development processes of the other four areas have been studied by researchers, so it is possible to accurately describe the impacts of those projects in the regions where they were situated. In addition, the FONATUR model has been used by the federal government for other developments around the Gulf of California at Puerto Peñasco, Sonora, and Nuevo Vallarta, Nayarit, with outcomes similar to those of the FONATUR projects. The broad regional economic benefits expected from FONATUR projects, according to some analysts, have not been realized $[5,6]$. Tourism has not been more dynamic than other export-oriented sectors such as financial services or manufacturing [6]. Although the tourism sector has generated important numbers of jobs, the low level of most tourism jobs (low pay, few benefits, and low skill) and seasonal fluctuations have reduced the positive impact of this employment [6]. The tourism sector's role in net foreign exchange generation has been limited, which is partly explained by leakage of profits through transnational companies [6]. The primary beneficiaries of the large tourism developments have been Mexican and foreign large companies rather than local companies and investors [5]. The development process of the resorts has not been transparent and rumors and stories of corruption and inefficiencies are common [5]. Finally, these tourism projects have not been successful in terms of stimulating regional development. Instead, most of the economic linkages that have developed have been with central Mexico and few local businesses have developed in the areas of the tourism projects. The resorts are economic enclaves in their regions. 
All previous FONATUR developments have stimulated significant internal migration and population growth. For example, between 1970 and 1995, annual population growth was $21 \%$ for Cancún, $14 \%$ for Los Cabos, $12 \%$ for Ixtapa, and $12 \%$ for Huatulco [6]. In that same period, Cancún grew from 2,600 to 311,700; Los Cabos grew from 2,600 to 71,000; Ixtapa grew from 4,900 to 87,100; and Huatulco grew from 1,500 to 25,200 [6]. In all cases, large irregular settlements of self-constructed housing with inadequate urban services have developed adjacent to the planned tourism development. These settlements are characterized by the lack of piped water or connection to sewage treatment systems, lack of pavement, and inadequate housing construction with dirt floors.

According to leading researchers of tourism in Mexico, "qualified permanent employment in the tourist sector generally excludes the local population," [6]. Only about one-third of tourism jobs can be considered skilled. So, local people usually end up in the low-paid, precarious positions that are insufficient to maintain a family adequately in the expensive resort towns [6, 9].

Although environmental quality, particularly beaches and beautiful islands with clean seawater, is necessary for the continuance of tourism [10], environmental deterioration is evident in all of Mexico's planned and traditional coastal tourism centers, particularly in Acapulco and Puerto Vallarta. Unsewered neighborhoods; surface, subsurface, and marine water pollution; inadequate solid waste collection and disposal facilities; groundwater contamination and depletion; destruction of mangroves; erosion; encroachment on and damage to ecosystems in the federally-owned beach and dune interface with the ocean; and overexploitation of marine species are typical problems. Some of these environmental effects are of concern in Baja California Sur and are noticeable in many areas of Los Cabos and in Loreto.

While Mexico has the legal structure in place for environmental protection of these coastal areas that are also the focus of tourism development, enforcement is a serious problem. Federal, state, and local agencies in Mexico frequently support and advocate sustainability [11]. For example, during the Zedillo administration (1995-2000), there was considerable promotion of the concepts of sustainable tourism and sustainable development [6]. This reflected the content of the 1992 Rio Summit (Agenda 21, for example) and movements for sustainable tourism with the development of the Charter for Sustainable Tourism that calls for conservation of natural and cultural heritage [10]. FONATUR, as with other federal agencies, incorporates sustainability into its mission statement, indicating that it is "the institution responsible for the planning and development of sustainable tourism projects of national impact" (http://www.fonatur.gob.mx).

Negative health effects are an outcome of the development of these resorts due to lack of access for workers and their families living in the marginal settlements to municipally provided potable water and lack of sewage connections and treatment systems, along with unpaved roads and substandard housing, have negative health effects. Particularly affected are the residents of the unplanned settlements that ring the luxury tourism developments. High infant mortality and gastrointestinal disease rates reflect this lack of adequate infrastructure, as well as the lack of proper healthcare facilities. 
All of the centrally planned tourism developments on Mexico's coasts have resulted in the marginalization of the local populations. The spatial plans produced luxury hotel, housing, and recreation zones that excluded local people. The planning and development were carried out by central authorities and imposed without adequate consideration of local people and their priorities. Land ownership in most areas passed to the government, foreign companies, and land speculators from elsewhere in Mexico. Most local people were only able to find employment in the low-paying service sector. Local entrepreneurs, likewise, tended to be excluded from the benefits: "because the locals lack experience, capital and market access, the most profitable levels of business (marketing, distribution, transport) tend to be controlled by non-local entrepreneurs," [7]. Due to the fast pace of development and massive migration into the region, local populations were simply overwhelmed and forced to adapt to the customs and needs of people from outside the community.

Local people also find themselves excluded from recreational resources they formerly used. Since the large tourism projects often occupy the land in front of the most attractive beaches, their physical construction often makes it impossible for local people to access these beaches that they had used for generations. This exclusion from local beaches can clearly be seen in the case of Club Med in Huatulco [12], and the Whales Inn and El Camino Real in Loreto. The high rise hotels that crop up along the beachfront in these resorts also negatively affect the viewshed and vistas enjoyed by local residents and visitors for generations [13].

\section{Los Cabos and BCS tourism development}

Although tourism began in Baja California Sur with sportfishing and mainland Mexicans traveling to La Paz for duty free shopping, the development of modern mass tourism is the result of the Mexican federal government's promotion in the late 1960s of a national plan to foster tourism as a means to stimulate regional development. The implementation of integrally planned tourism centers by the FONATUR initially included two locations in Baja California Sur, Loreto and Los Cabos. Financial, legal, and institutional stimuli were generously provided to the private sector in order to develop tourism destinations anchored on (mostly) foreign investment. Yet, such projects were disassociated from local conditions and communities and did not address environmental or social concerns. Nonetheless, the outcomes of this tourism development model are impressive in Baja California Sur.

Tourism flows reached unprecedented levels in the Los Cabos area, both in absolute and relative terms, in contrast to Loreto and the rest of the state. Although Los Cabos began as a small fishing and agricultural community, it has turned into one of Mexico's most dynamic tourism destinations, focusing on traditional tourism (sun, sand, beaches, golf, sportfishing, and entertainment). From accounting for $18 \%$ of total state of Baja California Sur visitors in 1976 (out of 274,456 ), the percentage rose to $29 \%$ in 1980 (out of 669,749 tourists), and $34 \%$ in 1985 (out of 446,663). In 1990, Los Cabos received nearly half of the 532,700 travelers who arrived in BCS, and $56 \%$ of the 560,300 visitors the 
following year [14]. That pattern continued during the 1990s and into the twentyfirst century.

The importance of the tourism sector in the BCS economy is clear: it includes $24 \%$ of businesses, $29 \%$ of employment, $22 \%$ of wages and salaries, and $32 \%$ of value. Tourism as measured by visitors in hotel accommodations has grown significantly, with 776,407 visitors in 1998 and 1,702,632 in 2008. The Los Cabos region was the key driver of this growth; by 2008, Los Cabos accounted for $73 \%$ of the state's tourism [15].

During the 2005-2008 period, tourist arrivals measured by hotel occupancy grew on average $12 \%$ per year. In 2007 , it dropped to a $3 \%$ increase as a result of the recovery of Cancún, a destination devastated by Hurricane Wilma in 2005 and whose demand was absorbed by Los Cabos. However, by 2008, the growth rate was $13 \%$ in $\mathrm{BCS}$, which was indicative of a generally favorable business environment for resorts and the tourism sector. However, the current economic crisis that began in 2007 hints at difficulties, especially for smaller firms [16], which lack collateral or support from parent or sister companies and cannot overcome the lack of demand and/or increasing costs and stay in business.

Cruise ship tourism has been on the rise in BCS, mainly because of Los Cabos, and this adds to the number of visitors to BCS. From 2005-2008, the cruise passenger growth rate was $32.4 \%$, and the number of cruises increased by $58 \%$. In 2008, Los Cabos received $94 \%$ of passengers and $77 \%$ of cruises that reached the state. According to FONATUR, Los Cabos is the second most important cruise ship port in Mexico and the aim is to strengthen its cruise tourism [17].

As a consequence of the dynamism of Los Cabos, a rapidly increasing number of jobs have been created, although wages in the state are below the national average [1]. This has been accompanied by an extremely high population growth rate-which averaged $10 \%$ annually during the last decadeas well as development of tourism, communications, and transportation infrastructure. In 2008, Los Cabos had over 13,000 hotel rooms, and its appeal to high-income foreign visitors unquestionably had an enormous economic impact. Revenues in just hotel occupancy alone meant 420.4 million dollars in 2008, 5\% less than the previous year, but $22 \%$ more than in 2005 [18].

The growing hotel industry and marketing campaigns have reinforced the internationally oriented nature of tourism, especially in Los Cabos. Foreign tourists were $71 \%$ of total visitors in 2008 in BCS, and Los Cabos hosted $91 \%$ of them. During the 2005-2008 period, Los Cabos visitors were $80 \%$ foreign and $20 \%$ national, which continues an ongoing trend. The United States and Canada constitute the main markets, although visitors from Europe and Asia also visit the area. Another feature of tourism growth is the high income level of visitors, especially in Los Cabos, as compared to other destinations in Mexico. Average per capita income was estimated at US\$77,000 [19]; depending on the season, daily expenditures average US\$250-450, which is nearly twice the average in the rest of Mexico [16].

In the early $1980 \mathrm{~s}$, there were approximately 30 hotels in the state. By 2004, there were 267 hotels and 13,701 rooms. By municipality, Los Cabos has most 
of the hotel infrastructure in BCS. Although in 2008 it had 39\% of the hotels in the state, it had $77 \%$ of all rooms, most of them four and five star-rated or above, mainly in large international resorts. Hotel occupancy rates were at about $67 \%$ to $70 \%$ [16], which have encouraged a continuous inflow of investment on hotel infrastructure.

Interregional differences in tourism infrastructure and number of visitors dictate the type of tourism policy orientation. Perspectives of growth for Los Cabos seem to be favorable in the midterm. The impact of the world economic crisis and that in California and the United States, which has severely hit BCS and Los Cabos, is still to be assessed. Also unclear are the effects of the H1N1 (swine) flu that greatly affected Mexico's tourism industry in early 2009. Both of these events contributed to the general turmoil surrounding a sector that so heavily depends on the exterior. To date, BCS has been spared the violence that has negatively impacted foreign tourism in other areas of Mexico, particularly the northern border region. However, some U.S. cruise lines in 2011 and 2012 have cancelled cruises from U.S. west coast ports to the Mexican Riviera, the ports of Los Cabos, Mazatlán, and Puerto Vallarta, due to violence in Mazatlán and Acapulco [20]. While Los Cabos remained untouched by the violence, it had cruise ship visits cancelled.

\section{Impacts of traditional tourism in Baja California Sur}

Enormous investments have been made and continue in the region and investors are mainly foreign. Most direct foreign investment has been channeled to Los Cabos, with some to La Paz [21]. For Los Cabos, this has meant a complete deconstruction of its natural landscape and remaking of its urban infrastructure. The high rates of economic and demographic growth have been accompanied by strong negative externalities and undesired by-products. These effects include the negative impacts that have accompanied other coastal tourism megaprojects throughout Mexico, including those around the Gulf of California. A 2006 report by the International Community Foundation [22], assessed current and future needs of Baja California Sur and documented many of the problems. The study shows a wide range of underserved social needs that could be improved with appropriate funding. Even if higher wages and job opportunities are available for the local population - which is constantly augmented by the incoming flow of people from Mexico's mainland - their level of education and quality of life is determined by their position as low-skilled laborers in the construction or tertiary activities sector. This situation has led to the state government's recognition that there has been inadequate planning of tourism growth, which has favored Los Cabos in detriment to other state regions [23]. It is also clear that economic activities related to tourism have had minimal benefits to most of the workers in the sector, including construction [24].

The success of Los Cabos as an international destination has made tourism increasingly important in the state's economy. Recently, investments in tourism and residential projects increased in $\mathrm{La}$ Paz and Loreto, but are behind the number in Los Cabos. At the same time, along with acknowledgement of the 
importance of the real estate and construction sectors linked to tourism as well as the building of residential complexes, there has been growing concerns. These relate to the lack of linkages among productive activities, overconcentration on those sectors [25], and also to the negative impacts on the environment and society.

Significant parts of the municipalities of Comondú and Mulegé (in the central and northern portions of the state), and areas adjacent to Loreto and La Paz, have also become investment magnets, especially in the last five years. Federal, state, and municipal governments promote and justify such developments in the name of job and infrastructure creation. Although large condominiums seem to be out of order in Los Cabos in order to preserve the low tourism density that makes it attractive, they have not been ruled out in other regions [16]. For instance, in La Paz a 6,000-room project with 2,000 in condominiums, in just its initial stage, was approved on a sand barrier peninsula across the bay from the La Paz city center. There was opposition to the project on several grounds. It was built on public property sold at a cheap price (about US $\$ 1.5$ per sq. meter) to developers who, at the low end, list a two-bedroom house for US\$200,000 [26]. The residential project represents a huge strain in terms of scarce resources such as water. With the project still under construction, the developers asked the city for 10 million liters of water, but only 260,000 could be supplied. The natural landscape was completely modified, or "Manhattanized." The project, an exclusive residential area targeted for foreigners, meant that access to land that was deemed emblematic of the area was lost to the public. This was reflected in significant community discontent [27].

In Cabo Cortés, closer to the Los Cabos tourist corridor, a 2.3 billion dollar U.S.-Spanish investment was authorized in 2008 to build 5,000 hotel rooms and 8,000 houses over a 12-to-15-year time span. In the seaside town of La Ribera, US $\$ 500$ million will be invested in a marina, golf course, and condominiums [16]. In this case, environmental concerns are significant since this project is likely to adversely impact the nearby natural protected area of Cabo Pulmo National Park that holds a rare and valuable coral reef. This is a clear case where imprudent tourism development has the potential to alter or destroy the pristine natural environment that was the original attraction of the area for tourism.

FONATUR has more than thirty years of involvement with efforts to develop Loreto as a center of international tourism. In 1976, FONATUR's plans called for a lineal project along the coast with Loreto as a traditional village and support center for Nopoló as the hotel zone and center of tourism activities. Puerto Escondido was identified as the nautical center. The project, however, languished for years. In the 2003-2005 period, FONATUR acquired a major foreign investor for Loreto and produced a new master plan for development of the area. Review of this new plan by academic researchers and community groups led to the conclusion that "the model of development that currently holds sway for Loreto - an economic growth pole based on megatourism projects - is archaic and not compatible with Loreto's social and natural context or with principles of sustainable development," [3]. Great concern was expressed that the traditional megaproject approach would negatively impact not only the superb 
natural environment and ecosystems of the Loreto area, but the rich local cultural heritage would be compromised.

Although increasing employment is clearly important, there should be a more careful screening of investment projects. This would ensure that jobs announced are actually jobs created. In addition, a follow up should be in place regarding the creation of more permanent-and well paid-direct and indirect employment. This is a relevant point given that most jobs are generated in the low-paying subsectors of construction and services at the start of a given project and, by definition, these places tend to be temporary. Also, workers who migrate from the mainland for these constructions jobs tend to remain with their families in irregular, marginal settlements and make a living as best they can.

There is a clear division of labor in the tourism industry according to qualifications that tend to favor non-locals. More empirical research is needed in this regard, but in a tourist destination where foreigners are the primary sales prospects for condominiums that are too expensive for most local residents, language and interpersonal skills that identify with potential buyers are crucial. Unfortunately, these two factors are not characteristic of most of the Mexican population arriving in Los Cabos in the quest for jobs, but they are for many foreigners. More highly educated and experienced Mexicans from the mainland or other megatourism areas also have a distinct advantage over local residents in the higher paid tourism positions

\subsection{Effects on natural and cultural resources}

Most of the large tourism investment projects in Baja California Sur have been located in the coastal zone. The FONATUR plans in the 1970s and more recent updates have envisioned longitudinal development along the coast with high rise hotels and condominiums, marinas, golf courses, and other amenities. Inevitably, unplanned development takes place and zones such as the tourist corridor of Los Cabos and parts of Loreto are characterized by strip development that is not only unattractive but blocks coastal views that are critical for enjoying the natural beauty of the sites.

Water is a critical factor for tourism development in the dry coastal areas of Baja California Sur. Most aquifers in the Los Cabos and Loreto regions are being depleted and threatened by declining water quality and quantity. The growing response by local authorities and investors involves water conservation measures, reclamation of wastewater, and, above all, installation of desalination plants. Mexico does not have national regulations for desalination and particularly problematic is disposal of the concentrated brine from the process back into the marine environment. Also of concern is the destruction of marine larvae and juvenile species by the intake pipes if drawing water directly from the ocean. The discharge of brine, for example, into the Loreto Bay National Park or Cabo Pulmo National Park, both of which are marine protected areas of great importance, is not prohibited under current regulations.

The coastal zone, the interface between the water and the land, is especially important ecologically. Mangroves and dunes and associated vegetation protect 
the land from tropical storms that hit the region each year, yet much of the tourism development has taken place in this area. Destruction of coastal vegetation on dunes and mangroves has increased shoreline erosion, reducing protection of coastal zones. Added to these impacts is uncontrolled encroachment onto the federal protected zone, which is 20 meters inland from the highest tide line. All of these actions by humans, among other problems, destroy or restrict access to marine turtle nesting sites [28, 29].

Another impact of the intense coastal tourism megadevelopments is that their construction and associated infrastructure often destroy or damage archaeological or cultural sites. Salvage archaeology of sites such as El Médano in Cabo San Lucas has provided important, but incomplete, information about the cultural heritage of the region [30]. However, there are not enough resources to properly survey and excavate the some 111 sites identified along the coast in Los Cabos, many of which are threatened by tourism development [30].

\section{Discussion}

Alternative tourism, with its low environmental and social impact, has been at the forefront of official pronouncements about and announcements of public policy related to tourism in BCS. It has also been recommended by many academic studies $[13,31]$. Yet, in practice, tourism activities have focused on the traditional megaresort model. The financial success for investors of the FONATUR tourism projects in coastal mainland Mexico and in Los Cabos, $\mathrm{BCS}$, has encouraged other investors to follow the megaresort approach. In this respect, the ongoing or proposed construction of over 40 tourism and secondhome megaprojects with multiple golf courses in an arid zone such as BCS seems incompatible with any true notion of sustainability. Prior to the 2000 s, the rest of the state lagged in following this process but investment projects and construction of resorts and second homes along other areas of the coastline show the spreading of the Los Cabos type of tourism model. Nevertheless, alternative tourism - including cultural, adventure, and ecological tourism that is based on small- and medium-size firms that are family owned and managed-is an excellent option for maximizing Baja California Sur's potential as a tourism destination while sustaining local society and culture and the critical natural resources of the region [3].

Municipalities such as Los Cabos recognize that they need to be a sustainable path and are beginning to embrace ecological planning and protection of resources that are critical to the tourism industry and also to environmental quality [32]. Researchers and community members are recognizing that slowing down the pace and scale of tourism development can help with mitigating the negative effects of large tourism development projects [3]. Government agencies and developers advocating projects in Baja California Sur frequently maintain that the proposed developments are "sustainable," [11]. The terms "sustainable" and "sustainable development" lack precision and objective indicators. A contribution that academic researchers can make is to develop measurable and 
objective indicators to help community members and policy makers determine what is sustainable and what is not sustainable.

\section{References}

[1] Instituto Nacional de Geografía, Estadística e Informática (INEGI). Baja California Sur. Actividades económicas, http://cuentame.inegi.gob.mx/ monografias/informacion/bcs/economia/default.aspx?tema $=$ me\&e $=03$

[2] Angeles, M., El desarrollo de las economías pequeñas ante la actual globalización, Documento de trabajo, Departamento de Economía, UABCS: La Paz, BCS, 2008.

[3] Ganster, P. The first capital of the Californias: The uncertain road ahead. Loreto, the Future of the Original Capital of the Californias, eds. P. Ganster, O. Arizpe and A. Ivanova, San Diego State University Press: San Diego, 2007.

[4] Martínez de la Torre, J.A. and Aguirre Osuna, L. Public administration and governance in the municipality of Los Cabos. Los Cabos: Prospective of a Natural and Touristic Paradise, eds. P. Ganster, A. Ivanova and O. Arizpe, San Diego State University Press: San Diego, 2012.

[5] Clancy, M.J. Tourism and development: Evidence from Mexico. Annals of Tourism Research, 26(1), pp.1-20, 1999.

[6] Brenner, L. and Aguilar, A.G. Luxury tourism and regional economic development in Mexico. The Professional Geographer, 54(4), pp.500-20, 2002.

[7] Brenner, L. State-planned tourism destinations: The case of Huatulco, Mexico. Tourism Geographies, 7(2), pp.138-64, 2005.

[8] Villegas, A. FONATUR and sustainable tourism in Loreto. Loreto, the Future of the First Capital of the Californias, eds. P. Ganster, O, Arizpe and A. Ivanova, San Diego State University Press: San Diego, 2007.

[9] Aguilar, A.G., Graizbord, B. and Sánchez Crispín, A. Las ciudades intermedias y el desarrollo de México, El Colegio de México: México, D.F., 1996.

[10] Gormsen, E. The impact of tourism on coastal areas. GeoJournal 42.1 (May), pp.39-54, 1997.

[11] Carruthers, D. The prospect, principles, and practice of sustainable development in Los Cabos. Los Cabos: Prospective of a Natural and Touristic Paradise, eds. P. Ganster, A. Ivanova and O. Arizpe, San Diego State University Press: San Diego, 2012.

[12] Long, V.H. Techniques for socially sustainable tourism development: Lessons from Mexico. Tourism and Sustainable Development: Monitoring, Planning, Managing, eds. J. G. Nelson, R. Butler and G. Wall, University of Waterloo: Waterloo, Ont., pp.201-18, 1993.

[13] Steinitz, C., Faris, R., Vargas-Moreno, J.C., Huang, G., Lu, S.Y, Arizpe, O., Angeles, M., Santiago, F., Ivanova, A., Gámez, A.E., Baird, K., Maddock III, T., Ajami, H., Huato, L., Haro, M.J., Flaxman, M., Ganster, P., Villegas, A. and López, C. Alternative Futures for Loreto, Baja 
California Sur, Mexico, Harvard University: Cambridge, 2005, www.futursalternativosloreto.org.mx

[14] Gámez, A.E. Los Cabos: Economía y población. Historia general de Baja California Sur. Economía, política, sociedad y cultura, Tomo III, comp. E. González, UABCS-Plaza y Valdés: La Paz, BCS, 2004.

[15] Gámez, A.E. and Ganster, P. Traditional tourism in Los Cabos: Opportunities and limitations of economic growth. Los Cabos: Prospective of a Natural and Touristic Paradise, eds. P. Ganster, A. Ivanova and O. Arizpe, San Diego State University Press: San Diego, 2012.

[16] Centro Mexicano de Derecho Ambiental (CEMDA). Los Cabos: Paraíso amenazado, http://www.cemda.org.mx/artman2/publish/ CEMDA_EN_LOS_MEDIOS_62/Los_Cabos_para_so_amenazado.php

[17] Fondo Nacional de Fomento al Turismo (FONATUR). Centro Integralmente planeado Los Cabos. Información general, http://www.fonatur.gob.mx/es/Des loscabos/des-loscabos.asp

[18] Gobierno del Estado de Baja California Sur. IV Informe de Gobierno del Ing. Narciso Agúndez Montaño. Anexo gráfico y estadístico, La Paz, BCS, 2009.

[19] Montaño, A., Pérez, J.C. and Higuera, D. 2009. Competitividad del desarrollo turístico de Los Cabos: Las oportunidades para las PyMES. Turismo, sustentabilidad y desarrollo regional en Sudcalifornia, eds. A.E. Gámez, A. Ivanova and A. Montaño, UABCS: La Paz, BCS.

[20] Aguilera, E. Cruise lines continue to nix Mexican ports. U-T San Diego, June 27, 2011.

[21] Angeles, M. and Gámez, A. Globalización y desarrollo regional, el caso del sector turismo en Baja California Sur. Globalización y regionalismo: economía y sustentabilidad, coords. A. Ivanova and A. Guillen, Porrúa: México, D.F., 2008.

[22] International Community Foundation (ICF). Baja California Sur Community-Based Opportunities and Needs, http://www.icfdn.org/ publications/na2006/index.htm

[23] Gobierno del Estado de Baja California Sur. Plan Estatal de Desarrollo 1999-2005, Secretaría de Promoción y Desarrollo Económico: La Paz, BCS, 1999.

[24] Gerber, J. A comparative analysis of two poles of tourism development: Loreto and Los Cabos. Loreto. The Future of the First Capital of the Californias, eds. P. Ganster, O. Arizpe and A. Ivanova, San Diego State University Press: San Diego, 2007.

[25] Angeles, M. La naturaleza de enclave de la economía sudcaliforniana con base en la matriz de insumo producto de 17 sectores, mimeo, Departamento de Economía, UABCS: La Paz, BCS, 2002.

[26] Paraíso del Mar. The Resort Neighborhoods of Paraiso del Mar, http://www.paradiseofthesea.com/en/project_info_project_summary.html

[27] Vigna, A. La gran mentira del "ecoturismo" en Centroamérica y México. Le Monde Diplomatique Mexico, 4(December), pp.20-22, 2008. 
[28] López-Castro, M.C., Villegas-Nava, F., González Payán, E., Comer Santos, K. and Nichols, W.J. Living on the edge: Sea turtles in the waters off Los Cabos, Baja California Sur. Los Cabos: Prospective of a Natural and Touristic Paradise, eds. P. Ganster, A. Ivanova and O. Arizpe, San Diego State University Press: San Diego, 2012.

[29] Tiburcio Pintos, G. and Briseño Dueñas, R. Sea turtles: Ancestral heritage of the Los Cabos region. Los Cabos: Prospective of a Natural and Touristic Paradise, eds. P. Ganster, A. Ivanova and O. Arizpe, San Diego State University Press: San Diego, 2012.

[30] Fujita, H. 2012. Prehistory and indigenous cultures. Los Cabos: Prospective of a Natural and Touristic Paradise, eds. P. Ganster, A. Ivanova and O. Arizpe, San Diego State University Press: San Diego, 2012.

[31] Ganster, P., Arizpe, O. and Ivanova, A. eds. Loreto, the Future of the Original Capital of the Californias. San Diego State University Press: San Diego, 2007.

[32] Arizpe, O., Fermán, J.L. and Rodríguez, R. The Ecological Land Use Plan of the Municipality of Los Cabos. Los Cabos: Prospective of a Natural and Touristic Paradise, eds. P. Ganster, A. Ivanova and O. Arizpe, San Diego State University Press: San Diego, 2012. 